\title{
The Development and Characterization of Zirconia-Silica Sand Nanoparticles Composites
}

\author{
Tahir Ahmad, Othman Mamat \\ Mechanical Engineering Department, Universiti Teknologi Petronas, Tronoh, Malaysia \\ E-mail: tahirengg4051@yahoo.com \\ Received February 7, 2011; revised March 14, 2011; accepted March 21, 2011
}

\begin{abstract}
The present study aims to develop zirconia-Silica sand nanoparticles composites through powder processing route and to study the physical properties, mechanical properties and microstructure of the composites. Zirconia based silica sand nanoparticles composite with 5, 10, 15 and $20 \mathrm{wt} . \%$ were developed through powder processing technique and sintered at $1500^{\circ} \mathrm{C}$ for two hours. A decreasing trend of green density however an improvement in sintered density was observed. Also the addition of silica sand nanoparticles with 20 wt. $\%$ increased the hardness up to $12.45 \mathrm{GPa}$ and microstructures indicated the diffusion mechanism of silica sand nanoparticles into pore sites of the composites.
\end{abstract}

Keywords: Zirconia-Silica Sand Nanoparticles Composites, Physical Properties, Mechanical Properties, Microstructures

\section{Introduction}

A great progress in dental restoration technique has been established by the use of ceramic materials since the 70's. Ceramics show some advantages like being the material that best mimic the bone tissue, although present low toughness when compared with the metallic materials. Alumina-zirconia composites are one of the relatively good and promising candidates for biomaterials application, due to biocompatibility and their mechanical properties that combine high flexural strength with high toughness. [1]

Hirvonen et al. [2] prepared nanocomposites by pressureless sintering method (PSM). The properties of the yttrium stabilized zirconia (Y-TZP)/zircon $\left(\mathrm{ZrSiO}_{4}\right)$ composites obtained by PSM are discussed in terms of its structure and fabrication condition that include the content of cordierite in initial mixture of cordierites and $\mathrm{Y}$ TZP nanopowders and sintering temperature. The interesting finding of this study concerns the coefficient of thermal conductivity of Y-TZP based composites with zircon, fabricated from the powder with more than 15 vol.\% content of cordierites, which appears to be lower than that of pure zirconia, despite the mixed materials exhibit high thermal conductivity. The DTA-TG examination confirmed excellent stability of the compo-site at elevated temperatures and proved the lack of the nanocom- posite oxidation.

Wen-Cheng et al. [3] studied $\mathrm{ZrO}_{2} /$ mullite composites with homogeneously dispersed $\mathrm{ZrO}_{2}$ grains from colloidal or sol-gel processes of the precursors, which were a mixture of colloidal pseudo-boehmite $(\gamma-\mathrm{AlOOH})$, zirconia and silicic acid gel, or prepared from dissociated zircon with alumina powder. Experimental results indicated that heat treatment from 1300 to $1600^{\circ} \mathrm{C}$ influence the growth of mullite and fine $\mathrm{ZrO}_{2}$ grains in ZMCs, especially for the composite prepared from solgel methods in which the $\mathrm{ZrO}_{2}$ grew from tens of nanometers to micrometer size. The growth of fine $\mathrm{ZrO}_{2}$ grains in a mullite matrix belongs to a mechanism of coalescence.

Pyda et al. [4] studied the reaction between carbon and titanium originated from zirconia-titania solid solution to produce $\mathrm{TiC}$ inclusions in situ in zirconia powders and dense materials. The co-precipitated powder composed of $1.5 \mathrm{~mol} \% \mathrm{Y}_{2} \mathrm{O}_{3}, 18 \mathrm{~mol} \% \mathrm{TiO}_{2}$ and $80.5 \mathrm{~mol} \% \mathrm{ZrO}_{2}$ was mixed with phenol-formaldehyde resin in an amount giving $200 \%$ excess of carbon in terms of stoichiometry of the carbothermal reduction of $\mathrm{TiO}_{2}$. The mixture was heated for $2 \mathrm{~h}$ at $1500^{\circ} \mathrm{C}$ in argon. The sintered bodies were composed mainly of tetragonal and monoclinic phase and contained nano-crystalline $\mathrm{TiC}$ inclusions which showed two different morphologies: oval and elongated. The role of oxygen vacancies in the in situ 
formation of elongated TiC inclusions is discussed. Improvement in the characteristics of the zirconia materials was obtained.

Anne et al. [5] prepared Yttria-stabilised zirconia (YTZP) based composites with carbide (WC) content up to 50 vol.\% from nanopowders by means of conventional hot pressing. The mechanical properties were investigated as a function of the WC content. The hardness increased from $12.3 \mathrm{GPa}$ for pure Y-TZP up to $16.4 \mathrm{GPa}$ for the composites with $50 \mathrm{vol} \% \mathrm{WC}$, whereas the bending strength reached a maximum of $1551 \mathrm{MPa}$ for $20 \mathrm{vol} . \%$ WC composites. The toughness of the composites could be optimised by judicious adjustment of overall yttria content by mixing monoclinic and $3 \mathrm{~mol} \% \quad \mathrm{Y}_{2} \mathrm{O}_{3}$ coprecipitated $\mathrm{ZrO}_{2}$ starting powders. An optimum fracture toughness of $9 \mathrm{MPa} \mathrm{m}{ }^{1 / 2}$ was obtained for a $40 \mathrm{vol} . \%$ WC composites with an overall yttria content of $2 \mathrm{~mol} \%$. The hardness, strength as well as fracture toughness of the ultrafine grained composites with a nanosized WC source was significantly higher than with micron-sized WC.

Liang et al. [6,7] prepared zirconia-mullite nanocomposite ceramics by in-situ controlled crystallization of $\mathrm{Si}-\mathrm{Al}-\mathrm{Zr}-\mathrm{O}$ amorphous bulk, which were first treated at $900-1000^{\circ} \mathrm{C}$ for nucleation, then treated at higher temperature for crystallization to obtain ultra-fine zirconiamullite composite ceramics. The effects of treating temperature and $\mathrm{ZrO}_{2}$ addition on mechanical properties and microstructure were analyzed. A unique structure in which there are a lot of near equated $\mathrm{t}-\mathrm{ZrO}_{2}$ grains and fine yield-cracks has been developed in the samples with $15 \%$ zirconia addition treated at $1150^{\circ} \mathrm{C}$. This specific microstructure is much more effective in toughening ceramics matrix and results in the best mechanical properties. The flexural strength and fracture toughness are $520 \mathrm{MPa}$ and 5.13 MPa.m ${ }^{1 / 2}$.

Zhan et al. [8] prepared the Y-TZP ceramic containing up to 30 vol. $\%$ TiC particles. A physical mixture of $3 \mathrm{~mol} \%$ $\mathrm{Y}_{2} \mathrm{O}_{3}-\mathrm{ZrO}_{2}$ powder with the $\mathrm{TiC}$ one was used. The cold isostatically pressed compacts were hot-pressed for $40 \mathrm{~min}$ at $1700^{\circ} \mathrm{C}$ under $30 \mathrm{MPa}$ in argon. Adding TiC particles to Y-TZP did not changed practically the bending strength and it improved the fracture toughness and hardness. With 20 vol.\% TiC particles the bending strength, fracture toughness and Vickers hardness of composites reached 1.1 GPa, 14.6 $\mathrm{MPa}^{0.5}$ and $16 \mathrm{GPa}$ respectively.

Haberko et al. [9] prepared a TiC-TZP composite starting from a solid solution powder of composition $3 \mathrm{~mol} \% \mathrm{Y}_{2} \mathrm{O}_{3}, 18 \mathrm{~mol} \% \mathrm{TiO}_{2}$ and $79 \mathrm{~mol} \% \mathrm{ZrO}_{2}$. The material, hot-pressed at $1500{ }^{\circ} \mathrm{C}$ under $25 \mathrm{MPa}$ in argon, showed a density of $+98 \%$, a hardness of $17 \mathrm{GPa}$, a Young's modulus of $221 \mathrm{GPa}$ and a fracture toughness of
4.1 MPa.m $\mathrm{m}^{0.5}$ in the presence of 8.3 vol.\% TiC inclusions. From above cited literature, no researcher still had used silica sand nanoparticles as reinforcement in zirconia based composites, therefore the present study's aim to develop zirconia based silica sand nanoparticles composites through powder processing technique and to investigate the physical, mechanical properties, microstructure and XRD analysis of the composites.

\section{Experimental Work}

The silica sand was originated naturally from Tronoh, Perak, Malaysia was washed with water to remove mud particles and dried in oven at $120^{\circ} \mathrm{C}$ for 3 hours. The dried silica sand was meshed about $600 \mu \mathrm{m}$ using sieve analysis. The $600 \mu \mathrm{m}$ size of natural silica was ground to nanoparticles by using dry ball mill with zirconium ball (beads) as grinding media. This high energy milling was known as one of the "top-down" nanoparticles type approach which generally relies on physical methods for their production.[10] In this work it was used to reduce the macro and micro-scale of silica sand to a nanoscale particle size (which is thereafter referred to "silica $\left(\mathrm{SiO}_{2}\right)$ nanoparticles"). The high-energy milling processes involve the comminution of bulk materials. The principle of comminution is centred on applying physical forces to bulk material so as to affect breakage into smaller sizes. The forces required to effect breakage are usually a combination of either impact or shear. Material is introduced into a milling chamber in which grinding (milling) media are contained. Milling occurs when the media is made to move either by stirring (using a rotor) or by shaking/vibrating the chamber. These results in the milling media making contact the bulk material thus imparting, depending on the milling parameters, either impact or shear forces on it. Breakage can occur through a variety of mechanisms and are generally described as attrition, abrasion, fragmentation or chipping, and occur both at the macro and microscopic level. [10] The nanoparticles obtained were verified by ZetaSizer, Nano ZS (ZEN 3600) (MALVERN) analyser. The ZetaSizer analyser is based on Photon Correlation Spectroscopy (PCS) or Dynamic Light Scattering (DLS) which is a process used to determine particle size by examining the diffusion rates (i.e. Brownian motion) of suspended particles. The technique utilizes a light source to illuminate the samples and scattered light is collected at a detector typically positioned at a fixed scattering angle. The latest generation of PCS/DLS instruments, such as the Zetasizer Nano, utilize a backscatter angle of 173 degrees. This optical configuration accommodates both high and low sample concentration, low sample volumes, and reduces the probability of intensity biasing, a phenomenon that occurs in 90 degree 


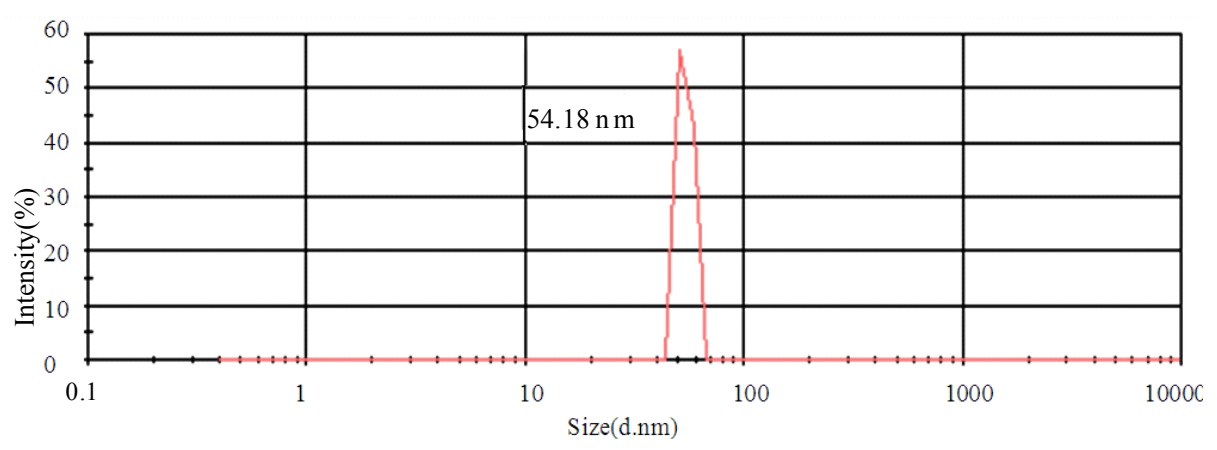

Figure 1. Particle size distribution of the silica sand nanoparticles (by intensity) produced from Zetasizer Nano Analyzer. The nanoparticles average size is $54.18 \mathrm{~nm}$.

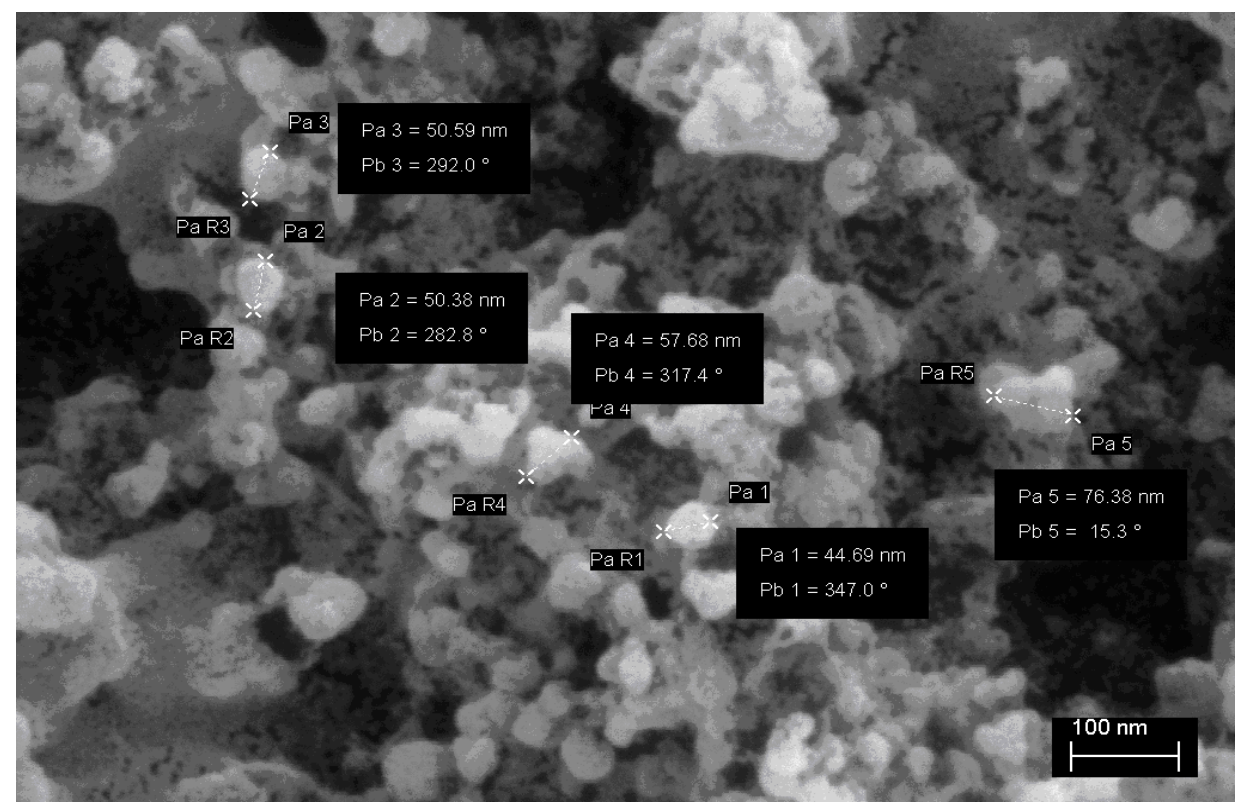

Figure 2. FESEM image of the ball-milled silica sand nanoparticles.

systems where the magnitude of light scattered by a large particle overshadows the light collected from the smaller particles. The nanoparticles size produced was then verified microscopically through Field Emission Scanning Electron Microscope (FESEM). The chemical composition of silica sand nanoparticles was analyzed using XRF technique. Silica sand nanoparticles were mixed with $\mathrm{ZrO}_{2}$ (Merck KGaA* 64271 Darmstadt Germany (zirconium (IV) oxide special grade Technipur $^{\mathrm{TM}}(\mathrm{M}=$ $123.22 \mathrm{~g} / \mathrm{mol}$, average particles size $400 \mathrm{~nm}$ and monoclinic crystalline phase) by using ball milling for 1 hour. Paraffin wax had been used as binding agent. The autopellet machine (capacity $80 \mathrm{kN}$ ) at $142 \mathrm{MPa}$ force by using metallic mould of diameter of $13 \mathrm{~mm}$ was used to make the composites. The following compositions were developed: pure $\mathrm{ZrO}_{2}, \mathrm{ZrO}_{2}-5 \mathrm{wt} . \%$ silica sand, $\mathrm{ZrO}_{2}$ $10 \mathrm{wt} . \%$ silica sand, $\mathrm{ZrO}_{2}-15 \mathrm{wt} . \%$ silica sand and $\mathrm{ZrO}_{2}-$ $20 \mathrm{wt} . \%$ silica sand nanoparticles. After the compaction, the green density of the samples was measured by the
Archimedes method. The samples were sintered at $1500^{\circ} \mathrm{C}$ for 2 hour in argon atmosphere respectively. The heating and cooling rates of sintered process were $5^{\circ} \mathrm{C} / \mathrm{min}$ and $10^{\circ} \mathrm{C} / \mathrm{min}$ respectively. After sintering process, the sintered densities were measured by Archimedes method. Microstructures of composites were analyzed by FESEM. XRD-Bruker AXS D8 Advance was used for identification of phases present in composites. The hardness was measured in accordance with ASTM C 1327-99 25 . The indentation load was $10 \mathrm{kgf}(98.1 \mathrm{~N})$ during fifteen seconds. After the diagonal length measurement, the values of the Vickers hardness $(\mathrm{GPa})$ were calculated, by the equation: [1]

$$
H v=0.0018544\left(P / d^{2}\right)
$$

where:

$$
\begin{aligned}
& H v=\text { Vickers hardness }(\mathrm{GPa}) \\
& P=\operatorname{applied}(\mathrm{N}) \\
& d=\text { arithmetic mean of the two diagonal length (mm). }
\end{aligned}
$$




\section{Results and Discussion}

\subsection{Morphology, Size and Distribution Analysis of Silica Sand Nanoparticles}

In this work silica sand particles, the macro and microscale were reduced to a nanoscale particle size (which then called as "silica $\left(\mathrm{SiO}_{2}\right)$ sand nanoparticles"). The high-energy milling processes involve the comminution of bulk materials. The principle of comminution is centred on applying physical forces to bulk material so as to affect breakage into smaller sizes. The forces required to effect breakage are usually a combination of either impact or shear. Material is introduced into a milling chamber, which contained grinding (milling) media are. Milling occurs when the media is made to move either by stirring (using a rotor) or by shaking/vibrating the chamber and contacts the bulk material thus imparting, depending on the milling parameters, either impact or shear forces on it. Breakage can occur through a variety of mechanisms and are generally described as attrition, abrasion, fragmentation or chipping and occur both at the macro and microscopic level. The silica $\left(\mathrm{SiO}_{2}\right)$ sand particle was quantitatively analysed by using the ZetaSizer, Nano ZS (ZEN 3600) (MALVERN) and its result is shown in (Figure 1). The average size for the silica particles was found to be $54.18 \mathrm{~nm}$, which qualified the product to be considered as $\mathrm{SiO}_{2}$ nanoparticles.

Morphology, size and distribution of the $\mathrm{SiO}_{2}$ sand nanoparticles are shown in Figure 2. It can be seen that some of $\mathrm{SiO}_{2}$ particulates which have fused together resulted from squeezing action of the ball-milling process. Thereafter ball-milled $\mathrm{SiO}_{2}$ nanoparticles formed wide range of shape from irregular or rod-like aggregates and agglomerates to rounded nanoparticles. The high surface energy of nanoparticles $\mathrm{SiO}_{2}$ is responsible for the aggregation. The conglomeration of submicron $\mathrm{SiO}_{2}$ particles is a spontaneous process because the Gibbs energy decreases during this process.

The FESEM image shown in Figure 2 also illustrates various structures of the $\mathrm{SiO}_{2}$ particles including spherical particles and irregular shape particles as well as agglomerates. This strong tendency for agglomeration which exists in the particles was induced by the Van-der-Waal forces acting between the individual particles. The morphology of such agglomerates may vary from chain-like (1-D) to heavily aggregated (3-D). This alone would not constitute a major problem since soft agglomerates held together by Van-der-Waal forces only are easily broken down in the next step of "dry" pressing that was incorporated in the powder processing. Several primary particles seem to cluster or fuse at their faces, which is possibly due to growth and "sintering" of individual crystals dur- ing the ball-milling process. EDS analysis on the silica sand rich phase shown in Figure 3, revealed the presence of high Si with little amount of Al.

\subsection{Chemical Composition of Tronoh Silica Sand Nanoparticles}

The chemical composition of the silica sand analyzed by XRF analysis gave the results shown in Table 1.

\subsection{Characterization of the Zirconia-Silica Sand Nanoparticles Composites}

\subsubsection{Zirconia Matrix Composites with Silica Sand Nanoparticles Property: Density}

A decrease in green density is shown in Figure 4, as increasing amount of silica sand nanoparticles, which indicates the presence of porosity in the green samples. Contrary to that, the rein-forcing of silica sand nanoparticles shows an improvement in densities after sintering. Also, after sintering, the porosity of the samples decreased and the presence of silica sand nanoparticles in zirconia probably reduce the mobility of zirconia grain boundaries during sintering and shows full densification. It also shows a better adhesion between zirconia matrix and silica sand nanoparticles which improved the sintered densities. Hirvonen [2] also observed such results of decreasing green densities and improvement in sintered densities in case of corderite $/ \mathrm{ZrO}_{2}$ composites.

\subsubsection{FESEM Analysis of the $\mathrm{ZrO}_{2}-\mathrm{SiO}_{2}$ Nanoparticles Composites}

Good interfacial integrity has been observed between the matrix and the reinforcement and homogeneous distribution of reinforcement can be seen form microstructures regardless of the size difference between matrix and the reinforcement. This is due to diffusion of silica sand nanoparticles in the pores sites of the composites as shown in Figure 5. In case of 15 and $20 \mathrm{wt} \%$ of silica sand zirconia based high resolution microstructures reveal the shrinkage of big pores into shallow inter-connected pores, with evidence of diffusion mechanism. Formation of bigger grains, necking and bridging structures was due to pre-liquid phase sintering.

\subsubsection{EDS Analysis of the $\mathrm{ZrO}_{2}-\mathrm{SiO}_{2}$ Nanoparticles Composites}

Figure 6 (a, b, c and d), shows the EDS analysis that reveals the presence of silica sand nanoparticles in 5, 10, 15 and 20 wt. $\%$ zirconia based composites. Increasing trend of silica sand nanoparticles are verified by the EDS analysis, as the curve of $20 \mathrm{wt} . \%$ silica sand is more pronounced as compared to 5 wt.\% silica sand nano- 
Table 1. Chemical composition of Tronoh silica sand nanoparticles.

\begin{tabular}{cccccccc}
\hline Compound & $\mathrm{Al}_{2} \mathrm{O}_{3}$ & $\mathrm{SiO}_{2}$ & $\mathrm{P}_{2} \mathrm{O}_{5}$ & $\mathrm{~K}_{2} \mathrm{O}$ & $\mathrm{CaO}$ & $\mathrm{TiO}_{2}$ & $\mathrm{Fe}_{2} \mathrm{O}_{3}$ \\
\hline wt.\% & 2.99 & 95.22 & 0.77 & 0.095 & 0.139 & 0.16 & 0.121 \\
\hline
\end{tabular}

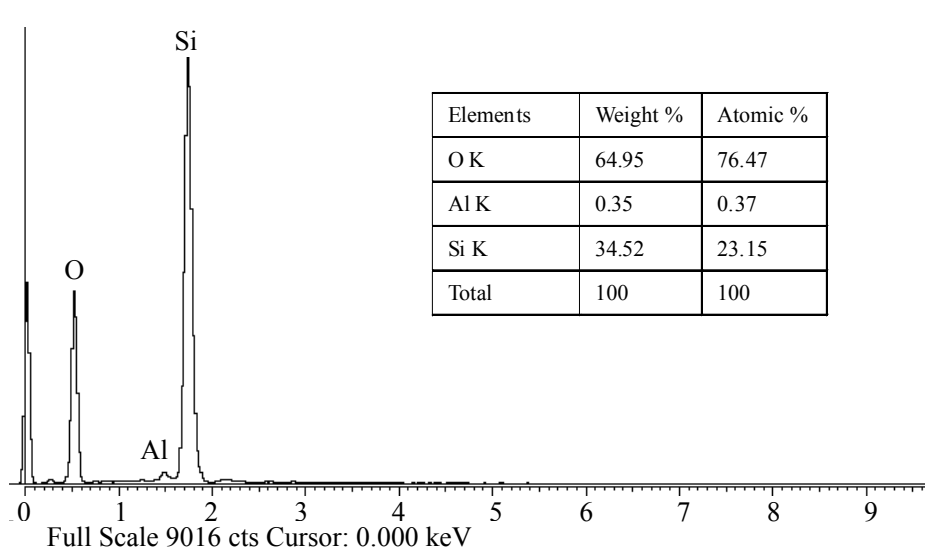

Figure 3. EDS analysis of the silica sand nanoparticles.

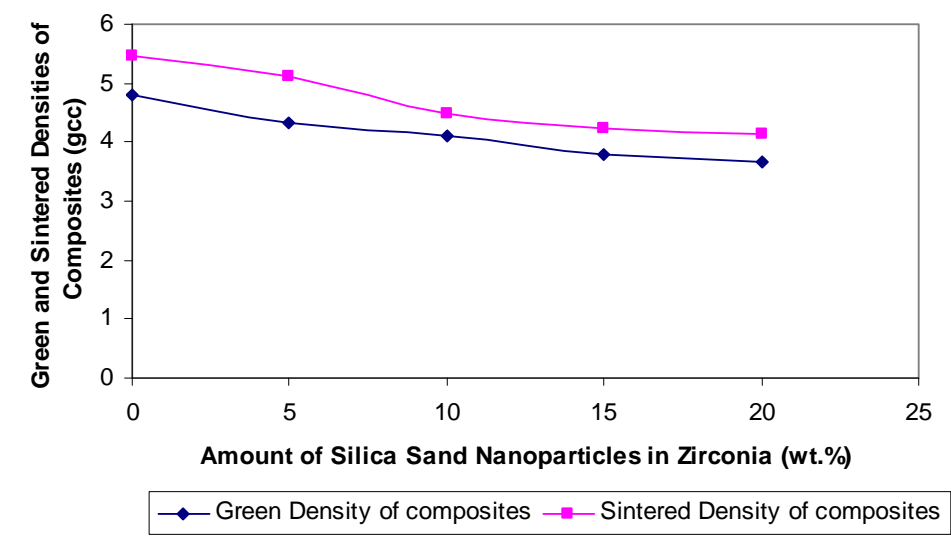

Figure 4. Green and Sintered densities of $\mathrm{ZrO}_{2}-\mathrm{SiO}_{2}$ composites.
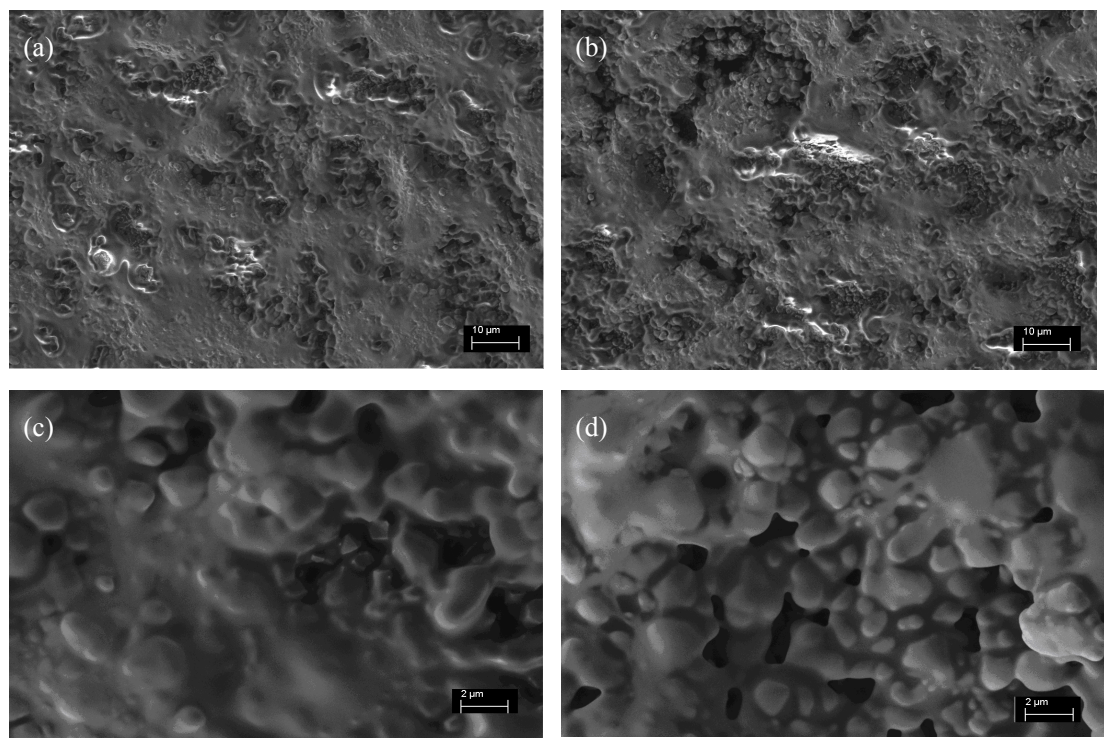

Figure 5. FESEM analysis of $\mathrm{ZrO}_{2}-\mathrm{SiO}_{2}$ nanoparticles composites with (a) 5wt.\% $\mathrm{SiO}_{2}$, (b) $10 \mathrm{wt} . \% \mathrm{SiO}_{2}$, (c) $15 \mathrm{wt} . \% \mathrm{SiO}_{2}$, (d) $20 \mathrm{wt} . \% \mathrm{SiO}_{2}$. 


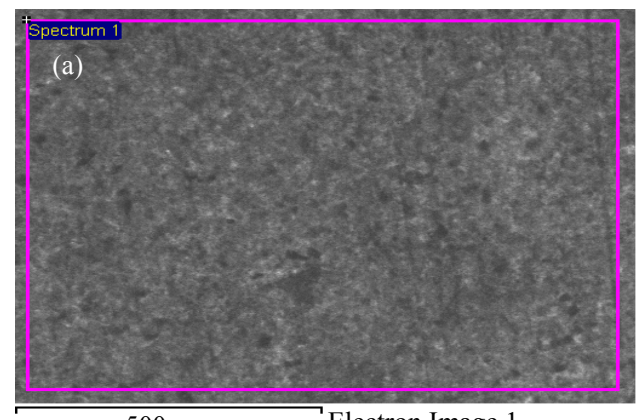

$500 \mu \mathrm{m} \quad$ Electron Image 1

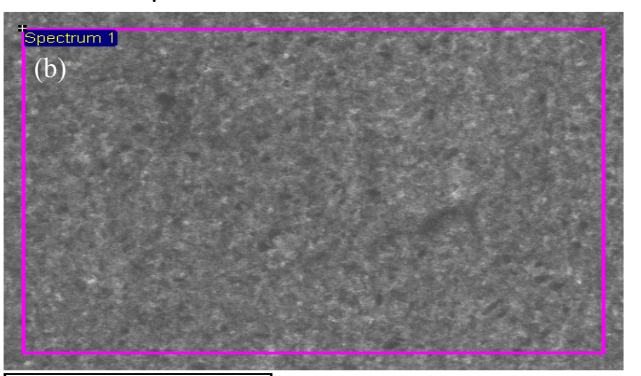

$500 \mu \mathrm{m} \quad$ Electron Image 1

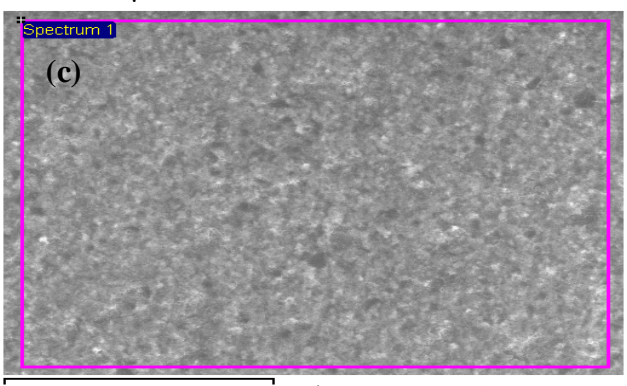

$500 \mu \mathrm{m}$

Electron Image 1

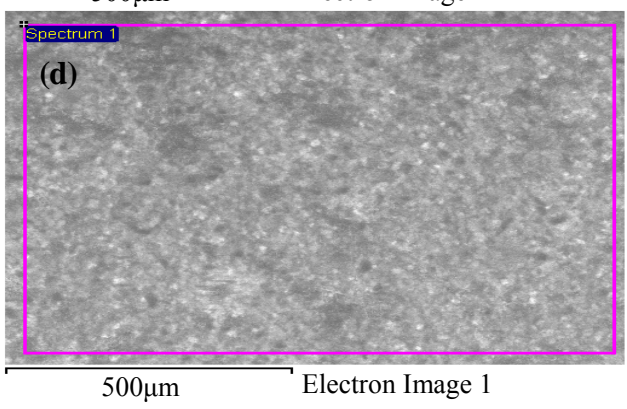

(a-1)

Spectrum 1

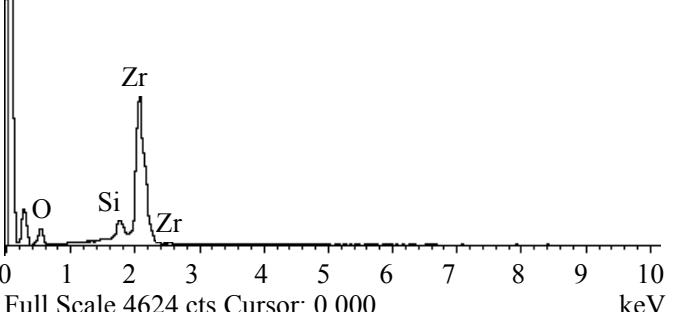

(b-1)

Spectrum 1

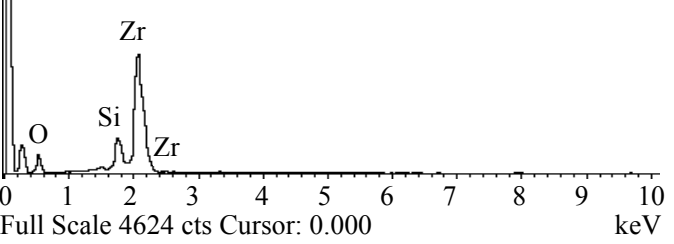

(c-1)

Spectrum 1

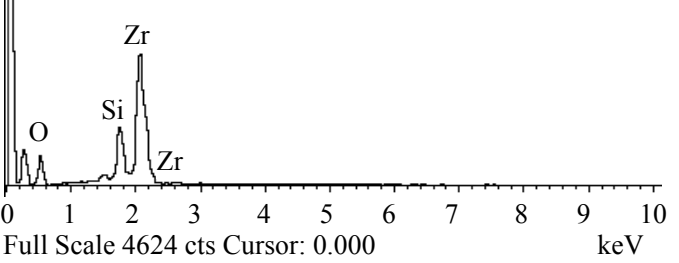

(d-1)

Spectrum 1

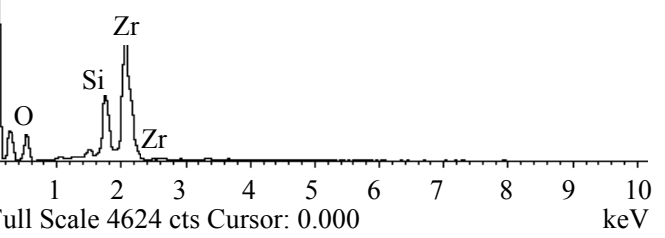

Figure 6. EDS analysis of $\mathrm{ZrO}_{2}-\mathrm{SiO}_{2}$ nanoparticles composites with (a) $5 \mathrm{wt} . \% \mathrm{SiO}_{2}$, (b) $10 \mathrm{wt} . \% \mathrm{SiO}_{2}$, (c) $15 \mathrm{wt} . \% \mathrm{SiO}_{2}$, (d) 20wt.\% $\mathrm{SiO}_{2}$.

particles in composites. It also verifies the homogeneity of the composites because all of EDS analysis of composites shows the peaks of silicon, oxygen and zirconium. The EDS analysis verified the presence of silicon, oxygen and zirconium, which may lead to the formation of $\mathrm{ZrSiO}_{4}$, Hirvonen [2] found such observation in case of corderite $/ \mathrm{ZrO}_{2}$ composites, which revealed the existence of $\mathrm{ZrSiO}_{4}$. It is also frequently indicated that $\mathrm{ZrSiO}_{4}$ is a proper candidate for high temperature ceramics, and as such, it matches the requirements concerning components of this "new composites".

\subsubsection{Hardness measurements of $\mathrm{ZrO}_{2}-\mathrm{SiO}_{2}$ Nanoparticles Composites}

An increasing trend of hardness was observed with increasing trend of silica sand nanoparticles in zirconiabased composites as shown in Figure 7. The increase in average hardness can be attributed primarily due to the presence of nano-size reinforcement particulates to higher tion. Both the matrix and reinforcement are ceramic materials, therefore this assist in obstructing localized plasconstrain to localized matrix deformation during indentatic deformation of the matrix during hardness test. Fur- 


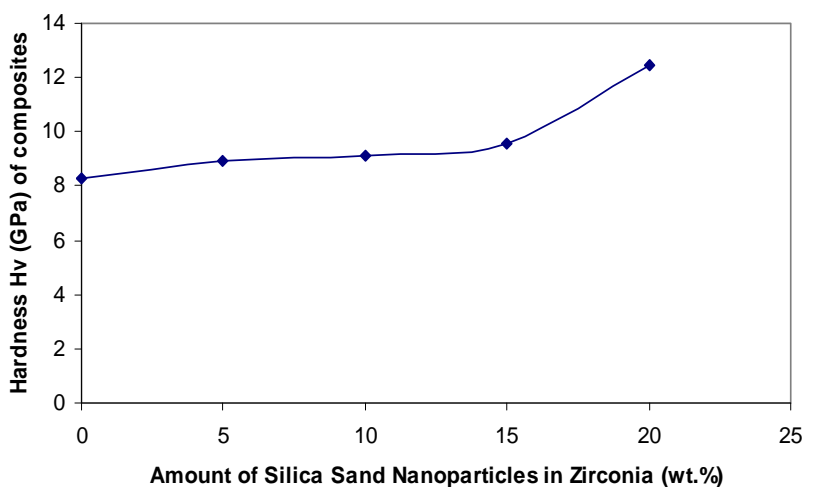

Figure 7. Hardness of $\mathrm{ZrO}_{2}-\mathrm{SiO}_{2}$ nanoparticles composites with (a) 5 wt. $\% \mathrm{SiO}_{2}$, (b) 10 wt. $\% \mathrm{SiO}_{2}$, (c) $15 w t . \% \mathrm{SiO}_{2}$, (d) 20wt.\% $\mathrm{SiO}_{2}$. thermore, the difference in coefficient of thermal expansion between the matrix and reinforcement particulates leads to higher dislocation density in the matrix and this resulted in the hardening of the matrix. [11,12] Higher hardness values imply good wear and scratch resistance. However, machining can be very hard to be done. The indentation load is critical in the measurement of hardness and fracture toughness using the indentation method. The amount of load could affect the indentation of the sample dimension and the microstructure of the material. [1] Solid loading plays an important role in determining the porosity and mechanical strength characteristics of the sintered samples. The strength of porous ceramic is also affected not only by the porosity, but also by forma-

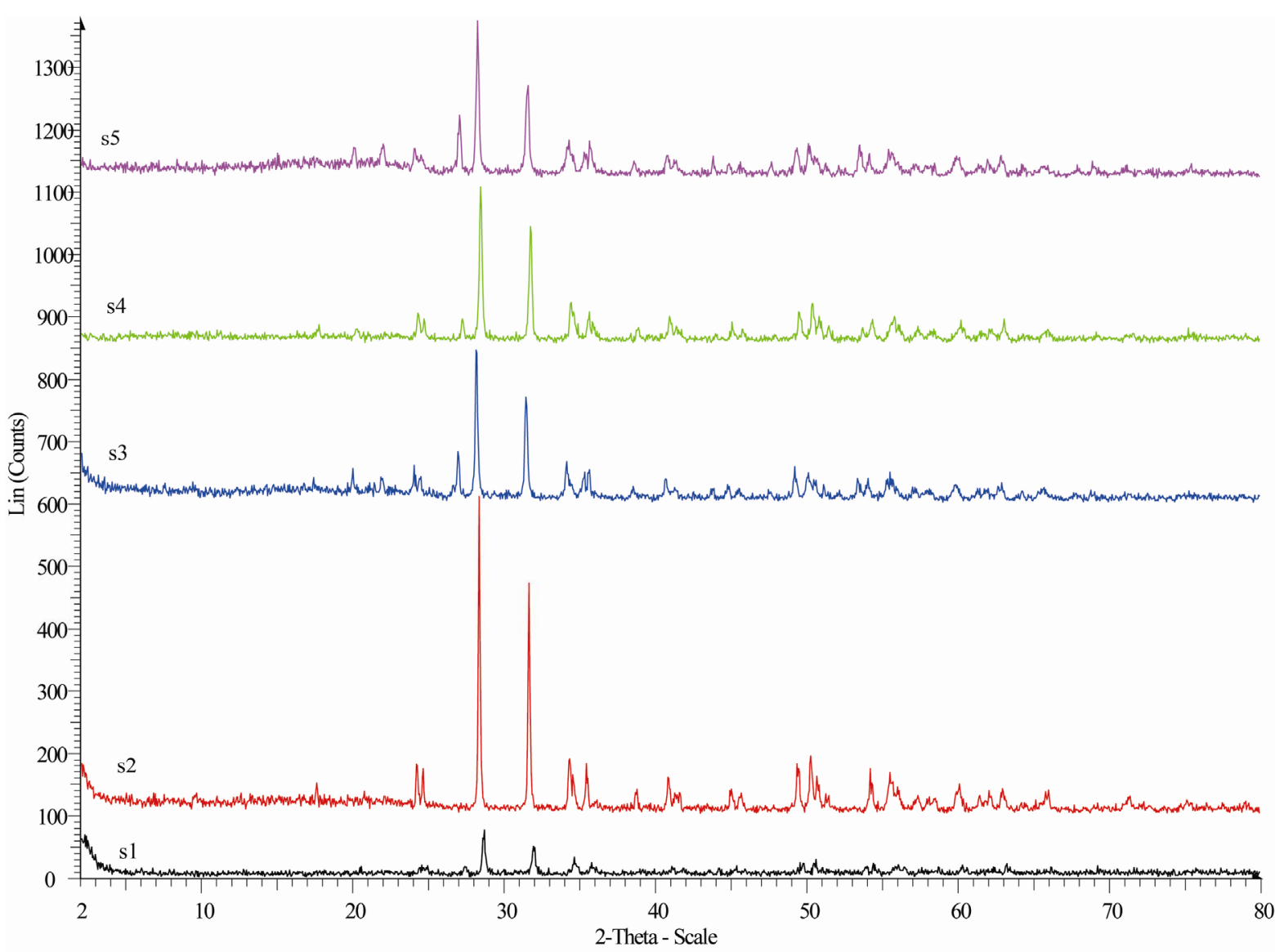

W s1 - File: s1.raw - Type: $2 \mathrm{Th} / \mathrm{Th}$ locked - Start: $2.000^{\circ}$ - End: $80.000^{\circ}$ - Step: $0.050^{\circ}$ - Step time Operations: Import

团 s2 - File: s2.raw - Type: $2 \mathrm{Th} / \mathrm{Th}$ locked - Start: $2.000^{\circ}$ - End: $80.000^{\circ}$ - Step: $0.050^{\circ}$ - Step time Operations: Y Scale Add 100 | Import

四 s3 - File: s3.raw - Type: $2 \mathrm{Th} / \mathrm{Th}$ locked - Start: $2.000^{\circ}$ - End: $80.000^{\circ}$ - Step: $0.050^{\circ}$ - Step time Operations: Y Scale Add 10 | Y Scale Add $10 \mid$ Y Scale Add 10 | Y Scale Add 10 | Y Scale Add

团 s4 - File: s4.raw - Type: $2 \mathrm{Th} / \mathrm{Th}$ locked - Start: $2.000^{\circ}$ - End: $80.000^{\circ}$ - Step: $0.050^{\circ}$ - Step time Operations: Y Scale Add 10 | Y Scale Add 10 | Y Scale Add 10 | Y Scale Add 10 | Y Scale Add

Wh s5 - File: s5.raw - Type: $2 \mathrm{Th} / \mathrm{Th}$ locked - Start: $2.000^{\circ}$ - End: $80.000^{\circ}$ - Step: $0.050^{\circ}$ - Step time Operations: Y Scale Add $10 \mid$ Y Scale Add $10 \mid$ Y Scale Add $10 \mid$ Y Scale Add 10 | Y Scale Add

Figure 8. XRD analysis of $\mathrm{ZrO}_{2}-\mathrm{SiO}_{2}$ nanoparticles composites. 
tion of sintering neck on the wall as well as the smaller pore size. The loading of the solid materials and sintering temperature significantly contributes to change of ceramic struts and porosity. [13]

\subsubsection{XRD Analysis of $\mathrm{ZrO}_{2}-\mathrm{SiO}_{2}$ Nanoparticles Composites}

XRD phase analysis of composites is shown in Figure 8. The peaks have been identified as belonging to phases of zirconia and silica. It was noted that as the weight percentage of reinforcement increases, the intensity peaks becomes stronger. XRD results also reveals that almost all the composites show similar peaks which result proper mixing of the composites constituents. Originally the zirconia powder was monoclinic and when it is sintered at $1500^{\circ} \mathrm{C}$ only a little bit phase trans-formation occur from monoclinic to tetragonal at this temperature. This quantity decreased with increasing temperature. This decrease could be due to grain growth of the $\mathrm{ZrO}_{2}$, lack of phase stabilizer, such as $\mathrm{CaO}$ or $\mathrm{MgO}$ and the thermal stress induced transformation and such behaviour has also been discussed by Wen-Cheng et al. [3].

\section{Conclusions}

The outcomes of this research show that the addition of silica sand nanoparticles to zirconia decreased the green densities. However, an improvement in sintered densities is observed. The incorporation of silica sand nanoparticles enhanced the hardness of the composites up to 12.45 GPa. From FESEM and EDS analysis, it was observed that the silica sand nanoparticles diffused into the porous sites of composites causing an improvement in mechanical properties. The XRD results show almost similar peaks for all composites. These observations indicate that silica sand nanoparticles may be used to develop new zirconia based composites better properties.

\section{Acknowledgements}

The authors would like to thank the Universiti Teknologi PETRONAS for providing necessary support in completing this research.

\section{References}

[1] M. C. C. de S. e B. de Moraes and C. Elias, "Mechanical Properties of Alumina-Zirconia Composites for Ceramic Abutments," Journal of Materials Research, Vol. 7, No. 4, 2004, pp. 643-649.

[2] A. Hirvonen, R. Nowak, Y. Yamamoto, T. Sekino, "Fabrication, Structure, Mechanical and Thermal Properties of Zirconia-Based Ceramic Nanocomposites," Journal of the European Ceramic Society, Vol. 26, No. 3, 2006, pp.
1497-1505. doi:10.1016/j.jeurceramsoc.2005.03.232

[3] J. W.-C. Wei, H. C. Kao and M. H. Lo, "Phase Transformation and Grain Coarsening of Zirconia/Mullite Composites," Journal of the European Ceramic Society, Vol. 16, No. 2, 1996, pp. 239-247. doi:10.1016/0955-2219(95)00157-3

[4] W. Pyda, "Microstructure and Properties of ZirconiaBased Nanocomposites Derived from a Powder Containing TiC Crystallised in Situ and Carbon," Ceramics International, Vol. 30, No. 3, 2004, pp. 333-342. doi:10.1016/S0272-8842(03)00105-6

[5] G. Anne, S. Put, K. Vanmeensel and D. T. Jiang, "Hardness, Tough and Strong $\mathrm{ZrO}_{2}-\mathrm{WC}$ Composites from Nanosized Powders," Journal of the European. Ceramic Society, Vol. 25, No. 1, 2005, pp. 55-63. doi:10.1016/i.jeurceramsoc.2004.01.015

[6] S.-Q. Liang, J. Zhong, X.-P. Tan and Y. Tang, "Mechanical Properties and Structure of Zirconia-Mullite Ceramics Prepared by In-situ Controlled Crystallization of Si-AlZr-O Amorphous Bulk," Transaction of Nonferrous Metals Society of China, Vol. 18, No. 4, 2008, pp. 799-803. doi:10.1016/S1003-6326(08)60138-7

[7] S.-Q. Liang, J. Zhong, X.-P. Tan and Y. Tang, "Preparation of Mullite-Zirconia Composites with Ultra Fine Grains Ceramics by In-situ Controlled Crystallization from Si-Al-Zr-O Amorphous Bulk," Nanoscience, Vol. 11, No. 1, 2006, pp. 32-37.

[8] G. D. Zhan, T. R. Lai., J. L. Shi, T. S. Yen, Y. Zhou and Y. Z. Zhang, "Microstructure and Mechanical Properties of Yttria Stabilized Tetragonal Zirconia Polycrystal Containing Dispersed TiC Particles," Journal of Materials Science, Vol. 31, No. 11, 1996, pp. 2903-2907. doi:10.1007/BF00356000

[9] K. Haberko, W. Pyda, Z. Pedzich and M. M. Bucko, "A TZP Matrix Composite with in Situ Grown TiC Inclusions," Journal of the European. Ceramic Society, Vol. 20, No. 14-15, 2000, pp. 2649-2654. doi:10.1016/S0955-2219(00)00159-X

[10] R. H. J. Hannink, "Nanostructure Control of Materials," CRC Press, Boca Raton, 2006. doi: $10.1533 / 9781845691189$

[11] W. Acchar, "Microstructure of Alumina Reinforced with Tungsten Carbide," Journal of Materials Science, Vol. 41, No. 11, 2006, pp. 3299-3302. doi:10.1007/s10853-005-5457-z

[12] S. M. L. Nai, J. V. M. Kuma, M. E. Alam, X. L. Zhong, P. Babaghorbani and M. Gupta, "Using Microwave-Assisted Powder Metallurgy Route and Nano-Sized Reinforcement to Develop High-Strength Solder Composites," Journal of Materials Engineering and Performance, Vol. 19, No. 3, 2009, pp. 335-341. doi:10.1007/s11665-009-9481-Z

[13] J. C. Han, C. Q. Hong, X. H. Zhang, J. Du, W. Zhang, "Highly Porous $\mathrm{ZrO}_{2}$ Ceramics Fabricated by a Camphene-Based Freeze-Casting Route: Microstructure and Properties," Journal of the European Ceramic Society, Vol. 30, No. 1, 2010, pp. 53-60. doi:10.1016/j.jeurceramsoc.2009.08.018 